\title{
MANCHESTER
}

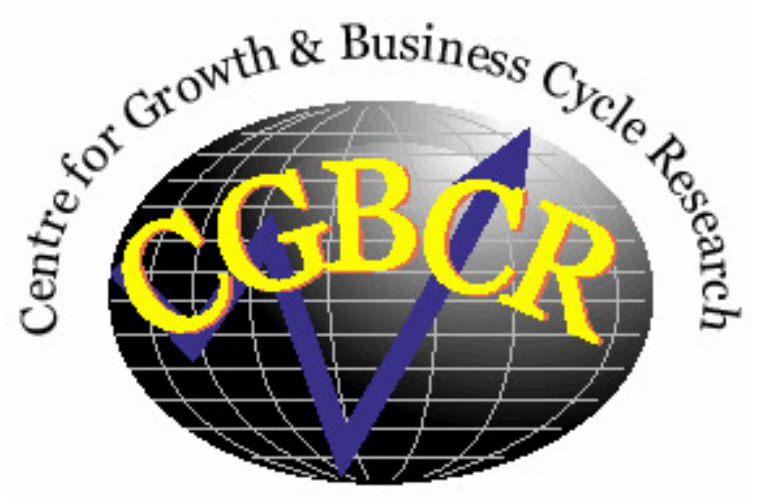

Discussion Paper Series

\section{Influential Price and Wage Setters, Monetary Policy and Real Effects \\ By}

\section{George J. Bratsiotis}

Centre for Growth and Business Cycle Research, Economic Studies,

University of Manchester, Manchester, M13 9PL, UK

November 2005

Number 063

Download paper from:

http://www.ses.man.ac.uk/cgbcr/discussi.htm 


\title{
Influential Price and Wage Setters, Monetary Policy and Real Effects
}

\author{
George J. Bratsiotis \\ University of Manchester, School of Social Sciences, Manchester M13 9PL, \\ UK, and Centre of Growth and Business Cycle Research (CGBCR).
}

August 2005

\begin{abstract}
Using a general equilibrium model this paper shows that when large monopolistic firms or unions perceive even a small influence on aggregate nominal variables, price targeting results in a higher equilibrium output than monetary accommodation. This is because price targeting increases, whereas monetary accommodation decreases, (i) the price elasticity of demand, (ii) the labour elasticity of demand and (iii) the elasticity of the wage with respect to households' total real income (i.e. wage, money transfers and profits). Within this framework, price targeting is shown to reduce the macroeconomic inefficiencies associated with monopolistic competition. The paper also shows that the standard approximation, that no single price or wage setter can affect nominal aggregates, is a good approximation provided, (a) at least a few hundreds of such large firms exist and more significantly (b) labour markets are decentralized or wage centralization is very low.
\end{abstract}

JEL classification: D4; E24, E31, E52, E58.

Keywords: Large monopolistic competitors; price and wage setting; monetary policy. 


\section{Introduction}

It is widely accepted in macroeconomic modelling that in economies where a very large number, $N$, of competitors exist, effects of the order $1 / N$ are 'negligible' in relation to the aggregate economy. This practice is a useful simplifying approximation that is based on the assumption of an 'infinitely large' number of firms and unions, in which case no single price or wage setter is large enough to perceive an influence on aggregate nominal variables, (see Dixit and Stiglitz 1977). More recently, a few attempts have been made to examine the qualitative implications of relaxing this standard approximation. For example, in computing the price elasticity of demand of monopolistic competitors, Yang and Heijdra (1993), allow each firm to perceive some influence on the average price index. This results in a lower price elasticity of demand than that derived in the Dixit-Stiglitz model. D'Aspremont et al (1996) show that in addition to the above effects, individual price decisions can also take into account income effects. Both of these models are focused on product diversity and the optimal degree of entry and so they are confined at the micro level. They show that the inclusion of such effects increases the monopolistic power of price setters, reduces the price elasticity of demand and raises the optimal price.

At the macro level, the presence of large price or wage setters has been shown to have significant qualitative implications that are dependent on monetary policy. When firms or unions are large enough to perceive even a small influence on aggregate nominal variables, monetary accommodation is shown to raise equilibrium unemployment by lowering the labour and price elasticities of demand, (Bratsiotis and Martin 1999, Iversen and Soskice 2000, Holden 2003, 
2005). ${ }^{1}$ This result is demonstrated to be robust even under the assumption of rational expectations or in the absence of nominal rigidities. However, scepticism may still remain as to whether, or the extent to which, any individual price or wage setter can perceive an influence on aggregate nominal variables.

This paper uses a microfounded general equilibrium model in order to examine thoroughly the conditions under which individual influential monopolistic industries and unions can generate real effects through their potential influence on nominal aggregates. The paper's main contribution to the recent literature is threefold. First, it introduces a new source through which influential wage setters can interact with aggregate demand, namely through the effects that wages have on households' non - wage income. The paper argues that given the standard assumption in general equilibrium models, that money transfers and profits of firms are distributed to households, (i.e. that households are share owners), influential unions should set wages in relation to the household's total real income. The latter consists of (i) the gains from being employed, (ii) money transfers and (iii) aggregate profits. The recent literature of large monopolistic competitors focuses mainly on (i), the wage income effect..$^{2}$ We show that the inclusion of the non-wage income effect (ii and iii) moderates the real effects shown in the earlier literature of large monopolistic competitors; yet it makes the role of monetary policy even more important as it provides another channel of interaction between price and wage setting and

\footnotetext{
${ }^{1}$ For an ealier literature see also, Driffill (1985) Calmfors and Horn (1985), Iversen (1998). Indeed, a number of more recent papers shows that considering the aggregate demand effects of single monopolistic competitors can produce some challenging qualitative results about policy implications and the structure of labour markets, (Lippi 1999, Guzzo and Velasco 1999, Coricelli, Cukierman, and Dalmazzo 2000, 2004, Holden 2003, 2005, Lippi 2003, Benassi, Chirco and Colombo 2002, Vartiainen, 2002, Knell 2002 etc.).

${ }^{2}$ At the macro level however, this effect is usually not examined within a general equilibrium framework as in this model (i.e. with unions maximising the households' objectives).
} 
aggregate demand. Second, the paper shows that the presence of influential price and wage setters strengthens the case for price targeting. Price targeting is shown to result in higher levels of equilibrium output than those implied using the standard approximation case, $(N=\infty)$. Price targeting is also shown to increase equilibrium output and reduce the inefficiencies associated with monopolistic competition. The third contribution of this paper is an attempt to quantify the significance of such effects. Using numerical simulations, we show that even in the presence of influential monopolistic competitors, the standard approximation of assuming an infinitely large number of firms and unions is still a good one, provided that, (a) at least a few hundreds of such firms operate in the economy and (b) labour markets are decentralized (i.e. union centralization is very low); otherwise, the paper shows that the interaction of monetary policy with price and wage setting can result in non-negligible real effects.

The rest of the paper is organised as follows: in section 2 , we introduce a microfounded general equilibrium that incorporates a monetary policy rule. Sections 3 examines the effects of large monopolistic price setters and wage setters and summarises the main effects in a number of propositions. Section 4, examines the effects of monetary accommodation and price targeting on equilibrium output and compares the macroeconomic inefficiencies implied by the two monetary regimes under the presence of influential monopolistic competitors; section 5 concludes. 


\section{A Microfounded General Equilibrium Model}

We consider a decentralized economy consisting of a finite number, $N$, of monopolistic firms, each producing a differentiated good, $j=1,2, \ldots N$. For simplicity, we assume that each sector $i,(i \in j)$, is represented by a typical household $h=1,2, \ldots, N$, who supplies $L_{h}$ units of labour to their respective firm $i$, consumes goods from all firms, receives a monetary transfer in the beginning of each period and receives an equal share of profits from all firms. Both the number of representative agents and firms are fixed and equal. ${ }^{3}$ The money supply is set according to a policy rule that follows either an accommodating monetary policy or price targeting. The economy then evolves around a game with three strategic agents: firms, unions and the monetary authority. The monetary authority first commits to a policy rule, then unions simultaneously select wages and finally firms simultaneously select the demand for employment and prices.

\subsection{Monetary Policy}

We use a simple monetary policy rule where the money supply grows according to,

$$
M=\left(\frac{P}{P^{*}}\right)^{\phi_{R}} M_{0}, \quad \phi_{R} \leq 1
$$

where $M_{0}$ and $M$ denote the initial and the final money stock respectively and $\phi_{R}$, where $R=P, A, T$, represents the policy parameter appropriate to the

\footnotetext{
${ }^{3}$ This notation simplifies the arrangement of population across sectors, without however restricting the representative households in each sector to be yeoman farmers, who produce and consume their own good.
} 
monetary regime pursued by the central bank. When $\phi_{P}=0$, the Central Bank follows a passive monetary policy or alternatively the money supply is set exogenously. With $P^{*}=1$ and $0<\phi_{A} \leq 1$, the Central Bank pursues an accommodating monetary policy, where $\phi_{A}=1$ represents full monetary accommodation. When $P^{*}$ is a positive constant and $\phi_{T}<0$, the money supply responds to deviations of the consumer price index from its fixed target level $P^{*}$, where $\phi_{T}$ represents the weight that the Central Bank attaches on price targeting. Finally, the case of 'strict' price targeting implies $\phi_{T} \rightarrow-\infty .{ }^{4}$

Equilibrium in the money market requires that the desired level of total money holdings of all households $\left(M_{H}\right)$, equals the total money stock supplied by the Bank, $(M)$, hence given our assumptions, $M_{H} \equiv \sum_{h=1}^{N} M_{h}=\sum_{i=1}^{N} M_{i}=M$.

\subsection{Households}

We assume that each typical household, $h$, derives utility from consuming a basket of all goods produced, real money balances and leisure. The utility of each representative household $h$ in their respective sector $i$ is,

$$
\begin{aligned}
U_{h} & =\left(C_{h}\right)^{\gamma}\left(\frac{M_{h}}{P}\right)^{1-\gamma}-L_{h}^{\theta}, \quad \gamma \in(0,1) ; \quad \theta>1 \\
\text { where, } \quad C_{h} & =(N)^{\frac{1}{1-\sigma}}\left(\sum_{j=1}^{N} C_{h j}^{(\sigma-1) / \sigma}\right)^{\sigma /(\sigma-1)}, \quad \sigma>1 \\
P & =\left(\frac{1}{N} \sum_{j=1}^{N} P_{j}^{(1-\sigma)}\right)^{1 /(1-\sigma)} .
\end{aligned}
$$

\footnotetext{
${ }^{4}$ Similar policy rules have been used in, Taylor $(1979,1980)$, Alogoskoufis and Smith (1991), Bratsiotis and Martin (1999), Iversen and Soskice (2000), Holden (2005) etc.
} 
$C_{h j}$ is the consumption of product $j$ by household $h ; C_{h}$ is the total consumption basket of this household and $\sigma$ is the elasticity of substitution between consumption goods in the utility. For simplicity, all consumption goods enter the utility function symmetrically. Each household maximizes utility by taking prices and wages as given and subject to the following budget constraint:

$$
\sum_{j=1}^{N} P_{j} C_{h j}+M_{h}=W_{i} L_{h}+m M_{h, 0}+\sum_{j=1}^{N} V_{h j} \equiv I_{h} .
$$

$M_{h, 0}$ and $M_{h}$ denote the initial money holdings and the end of period desired money of household $h$, respectively. The initial money transfers of each household grow, by the end of the period, at the rate $m=\frac{M}{M_{0}}=\left(\frac{P}{P^{*}}\right)^{\phi_{R}}$, as determined by equation (1). $W_{i}$ is the wage in sector $i$ and given our simplification assumption that each sector $i$ is represented by a household $h, L_{h}=L_{i}$ denotes the labour supplied by each worker $h$ in their respective firm $i ; V_{h j}$ denotes the share of profits from each firm $j=1,2 . . N,(i \in j)$, distributed to each household $h$. Based on the maximization problem described by equation (2)-(5), the typical household $h$ chooses the desired levels of consumption of good $j$ and money balances,

$$
\begin{aligned}
C_{h j} & =\frac{I_{h}-M_{h}}{N P}\left(\frac{P_{j}}{P}\right)^{-\sigma}, \\
M_{h} & =(1-\gamma) I_{h} .
\end{aligned}
$$

Substituting equation (7) into (6) we obtain,

$$
C_{h j}=\frac{\gamma I_{h}}{N P}\left(\frac{P_{j}}{P}\right)^{-\sigma}
$$


Aggregating over all households $h=1,2 \ldots N$, located in all industries, using $C_{j}$ $=\sum_{h=1}^{N} C_{h j}, \sum_{h=1}^{N} M_{h}=M_{H}$ and equation (7), we obtain the total consumption of each product $j$,

$$
C_{j}=\frac{\gamma M_{H}}{(1-\gamma) N P}\left(\frac{P_{j}}{P}\right)^{-\sigma}
$$

Equilibrium in the market for each product $j$, requires $C_{j}=Y_{j}$. Using this and the money market equilibrium condition, $M_{H}=M$, we obtain,

$$
Y_{i}=\frac{\gamma}{(1-\gamma) N}\left(\frac{M}{P}\right)\left(\frac{P_{i}}{P}\right)^{-\sigma}, \quad i \in j
$$

Equation (10) is the familiar product demand equation in models of imperfect competition, increasing in aggregate demand but decreasing in its relative price and in the number of products entering the household's consumption basket.

\section{$3 \quad$ Influential Price and Wage Setters}

The standard approximation, based on the assumption that a very large number of firms and unions operate at any time in any economy, neglects two effects. First, that no single firm $i$ or union $k$, can have even the smallest effect on nominal aggregate variables, hence $d P / d P_{i}=d W / d W_{k}=0$. Second, that cross price (wage) elasticities are removed, hence each industry (union) must also ignore cross price (wage) interactions, $d Y_{i} / d P_{j}=d P_{i} / d P_{j}=0$, which is a strong ad-hoc assumption particularly in oligopolistic models. As we show next, if price or unions are large to perceive even a very small influence on aggregate nominal variables there can be substantial qualitative results arising from relaxing the standard approximation. 


\subsection{Influential Price Setters and Employment}

For simplicity, the production technology in each industry $i$ is given as,

$$
Y_{i}=A L_{i}
$$

where $A$ is an exogenous parameter and $L_{i}$ is the labour employed in firm $i$,

$$
L_{i}=\frac{\gamma}{(1-\gamma) N A}\left(\frac{M}{P}\right)\left(\frac{P_{i}}{P}\right)^{-\sigma} .
$$

Each firm faces a standard profit maximization problem,

$$
V_{i}=P_{i} Y_{i}-W_{i} L_{i}
$$

Relaxing the standard approximation $\left(d P / d P_{i}=0\right)$ and denoting the resulting variables by a hat, $(\widehat{x})$, we derive the price set by each firm $i$ when the latter recognizes even a small influence on the CPI,

$$
\widehat{P}_{i}=\frac{\widehat{\mu}_{i} W_{i}}{A}, \quad \widehat{\mu}_{i}=\left(1-\frac{1}{\widehat{\varepsilon}_{i}}\right)^{-1}
$$

The price elasticity of demand is, $\widehat{\varepsilon}_{i} \equiv-\frac{P_{i}}{Y_{i}} \frac{d Y_{i}}{d P_{i}}=\varepsilon_{i}-\psi_{i}$, and so it consists of two effects, (a) the direct effect of the own price elasticity of demand, $\varepsilon_{i}=$ $-\frac{P_{i}}{Y_{i}} \frac{\partial Y_{i}}{\partial P_{i}}=\sigma$ and (b) the CPI effect, $\psi_{i}=\left(\frac{P}{Y_{i}} \frac{\partial Y_{i}}{\partial P}+\frac{M}{Y_{i}} \frac{\partial Y_{i}}{\partial M} \frac{P}{M} \frac{\partial M}{\partial P}\right)\left(\frac{P_{i}}{P} \frac{\partial P}{\partial P_{i}}\right)$. The CPI effect measures the effect that the price of each firm $i$ can have on its own product demand, when that firm perceives even a very small influence on the CPI. Using the CPI index, as given in equation (4), and the above information 
we obtain, ${ }^{5}$

$$
\begin{aligned}
\widehat{\varepsilon}_{i} & =\sigma-\psi_{i}, \quad \psi_{i}=\left(\sigma-1+\phi_{R}\right) S_{i}, \\
S_{i} & =\frac{\left(P_{i} / M\right)^{1-\sigma}}{\left(\sum_{j=1}^{N} P_{j} / M\right)^{1-\sigma}}, \quad i \in j .
\end{aligned}
$$

$S_{i}$ denotes each household's budget share spent on product $i$, and since goods enter the utility symmetrically it is determined by the relative price of each product. At the symmetric equilibrium, where $P_{i}=P, W_{i}=W, \varepsilon_{i}=\varepsilon$ and $S_{i} \rightarrow S=1 / N$

$$
\begin{array}{ll}
\widehat{P}=\frac{\widehat{\mu} W}{A}, & \widehat{\mu}=\left(1-\frac{1}{\widehat{\varepsilon}}\right)^{-1}, \\
\widehat{\varepsilon}=\sigma-\psi, & \psi=\left(\sigma-1+\phi_{R}\right) / N .
\end{array}
$$

At the symmetric equilibrium, $\widehat{\varepsilon}$ is shown to be a function of (i) the number of industries recorded in the CPI, $(N)$, (ii) the monetary policy parameter $\left(\phi_{R}\right)$ and (iii) the elasticity of substitution $(\sigma)$. The standard approximation case, with no influential agents, reduces to just the latter constant, $\varepsilon=\sigma$. As $N \rightarrow$ $\infty, \widehat{\varepsilon} \rightarrow \varepsilon=\sigma$ and $\psi \rightarrow 0$; in which case $d \widehat{\varepsilon} / d \phi_{R}=0$, indicating that the monopolistic power of each industry is too small to recognise any response in monetary policy. However, for a small and finite number of industries or unions, $\phi_{R}$ can play a crucial role in determining the size of $\widehat{\varepsilon}^{6}$

\footnotetext{
${ }^{5}$ For a detailed derivation see Appendix A.

${ }^{6}$ Note that throughout this model we only consider values of $\widehat{\varepsilon}>1$, (see also Proposition $1)$. This is based on the standard macroeconomic assumption of gross substitutability between goods in the consumption basket $(\sigma>1)$. A perhaps more interesting role is that played by the elasticity of substitution in the factors of production (i.e. capital and labour) though this is beyond the scope of this paper. For a model of profit sharing and wage bargaining where this latter elasticity is shown to be important see Holmlund (1990).
} 
Proposition 1 In the presence of influential price setters, $1<N<\infty$, (i) monetary accommodation raises the CPI effect whereas price targeting reduces the CPI effect; (ii) price targeting results in a higher price elasticity of demand, $\left(\widehat{\varepsilon}_{T}>\widehat{\varepsilon}_{A}\right)$ a lower mark-up, $\left(\widehat{\mu}_{T}<\widehat{\mu}_{A}\right)$, and a lower price $\left(\widehat{P}_{T}<\widehat{P}_{A}\right)$ than those implied by monetary accommodation.

Proof. See Appendix C.

Proposition 2 In the presence of influential price setters, $1<N<\infty$, (i) monetary accommodation results in a lower price elasticity of demand, $\left(\hat{\varepsilon}_{A}<\varepsilon\right)$, a higher mark-up $\left(\widehat{\mu}_{A}>\mu\right)$, and a higher price $\left(\widehat{P}_{A}>P\right)$ than those implied by the standard approximation $(N=\infty)$; (ii) For values $\phi_{T}<-(\sigma-1)$, price targeting results in a higher price elasticity of demand, $\left(\varepsilon<\widehat{\varepsilon}_{T}\right)$, a lower markup $\left(\widehat{\mu}_{T}<\mu\right)$, and a lower price $\left(\widehat{P}_{T}<P\right)$, than those implied by the standard approximation.

Proof. See Appendix C.

The intuition of this result is that price targeting makes price setting more sensitive to each industry's product demand, thus raising $\widehat{\varepsilon}$. This is because the stricter is monetary policy the lower is aggregate demand and hence product revenue, $Y_{j} P_{j}$. As influential industries recognize even a small impact on aggregate price, the stricter is monetary policy with respect to the aggregate price the more sensitive influential industries become in their price setting. Conversely, a higher $\phi_{R}$ is shown to reduce the price elasticity of demand, as accommodating monetary policy feeds into the monopolistic power of influential price setters. ${ }^{7}$

\footnotetext{
${ }^{7}$ The intuition here is consitent with the results in Bratsiotis and Martin (1999), Iverson and Sosckice (2000) Holden (2003), (2005).
} 


\section{[ Table 1. Monetary Policy and Price Mark-ups]}

Table 1 , estimates the size of $\widehat{\varepsilon}$, and $\widehat{\mu}$, in relation to their counterparts, $\varepsilon$ and $\mu$, implied by the standard approximation, $(K=N=\infty)$. As propositions 1 and 2 suggest, monetary accommodation is shown to reduce $\widehat{\varepsilon}$ and hence raise $1-\widehat{\varepsilon} / \varepsilon$, whereas stricter values of price targeting can raise $\widehat{\varepsilon}$ even above $\varepsilon$, lower $\widehat{\mu}$ and raise $1-\widehat{\mu} / \mu .^{8}$ However, the results also suggest that in economies with decentralized labour markets $(K=N)$, a few hundreds of such firms operating in the economy, is a sufficient number to minimise the effects of single price setters on aggregate nominal variables, in which case the standard approximation is a good one.

\subsection{Influential Unions and Wage Setting}

Wages and employment are determined in a monopolistic union context, where unions set wages and firms set the demand for employment and prices. There are $k=1,2,3 \ldots K$ unions, where $K \leq N$. For simplicity, the degree of wage centralization, $\zeta$, is captured by the effect that a single wage setter $k$ has on the average wage, $\zeta=\frac{W}{P} \frac{d P}{d W} \frac{W_{k}}{W} \frac{d W}{d W_{k}}$, (i.e. Bratsiotis and Martin 1999, Knell 2002, Holden 2005). Since with constant returns, $\frac{W}{P} \frac{d P}{d W}=1$, at the symmetric equilibrium the degree of wage centralization simplifies to $\zeta=\frac{W_{k}}{P} \frac{d P}{d W_{k}}=1 / K$. This implies that when labour markets are completely decentralized, $K=N$, then $\zeta=1 / K=1 / N$, and each firm is represented by its own union. At the other extreme, full wage centralization implies $K=1$, hence $\zeta=1$, and all $N$

${ }^{8}$ The base values used in all tables are, $\theta=1.3, \gamma=0.85$, and $\sigma=7$. In interpreting tables $1-4$, note that the closer is $\widehat{x}$ to $x$ the closer to zero is the value $(1-\widehat{x} / x)$ and hence the more appropriate is the standard approximation used widely in the literature. Positive values in the tables indicate that $\widehat{x}<x$ wheras negative values indicate that $\widehat{x}>x$. 
firms are covered by a nation-wide union.

In maximizing their members' indirect utility, influential unions must take into account their members' total real income, $I_{k}$. This consists of the real gains from being employed $\left(W L_{k} / P\right)$, real money transfers $\left(M_{k} / P\right)$ and real profits $\left(\sum_{j=1}^{N} V_{k j} / P\right)$. We will refer to the first of these as wage-income, whereas to the latter two as the household's non-wage income. The recent literature of large monopolistic competitors recognizes only the effect of wages on wageincome. ${ }^{9}$ The inclusion of the non-wage income effect is a novelty in this recent literature and is based on the following rationale. Since real money balances are part of a household's welfare and influential unions can affect aggregate nominal variables, then influential unions must also take into account how their wage decisions will affect their members' real money balances. In addition, general equilibrium models of imperfect competition assume that profits from monopolistic firms are distributed to households, usually with each household holding an equal share of profits from each firm; this is shown as an extra form of income in the household's budget constraint (see Dixit and Stiglitz 1977 and Blanchard and Kiyotaki 1987). Implicitly, this is based on the assumption that each household is a share holder that participates in an employee economy-wide share ownership. In this paper we argue that in an economy where households participate in share ownership, influential unions must also take into account the effect that their wage setting will have on their members' real profits. ${ }^{10}$

\footnotetext{
${ }^{9}$ Note that this may be also due to the fact that the existing literature does not typically derive this effect within a general equilibrium model, where unions maximise the household's indirect utility, as in this model, (see Bratsiotis and Martin 1999, Iversen and Soskice 2000, Holden 2000, 2003, 2005, Coricelli, Cukierman, and Dalmazzo 2000, 2001).

${ }^{10}$ The wage-real profit effect here differs from the conventional literature of profit sharing or wide-share ownership in three respects. Firstly, because of the way we introduce this effect in our model. We use a general equilibrium model where unions maximise the households' welfare subject to their budget constraint. It is through the latter (i.e. the household's total income) that the wage-profit effect enters endogenously in this model. In the literature of
} 
The household's indirect utility can be obtained by substituting equation (8), (3) and (4) into (2) and re-arranging using the fact that $L_{h}=L_{i}$, we obtain $U_{h}=\frac{\widetilde{\gamma} I_{h}}{P}-L_{i}^{\theta}$ and since unions aim to maximize the utility of all their members, each union $k$ maximizes,

$$
U_{k}=\frac{\widetilde{\gamma} I_{k}}{P}-L_{k}^{\theta}
$$

where $\widetilde{\gamma}=\gamma^{\gamma}(1-\gamma)^{1-\gamma}$ is the constant marginal utility of real wealth and $I_{k} / P$ and $L_{k}$ are the total real income and employment of households covered by union $k$, respectively. Given the above assumptions, the first order condition of equation (17) is,

$$
-\widetilde{\gamma} \widehat{\xi}_{k}+\frac{\theta \widehat{\lambda}_{k}}{\left(I_{k} / P\right)} L_{k}^{\theta}=0
$$

where, $\widehat{\xi}_{k} \equiv-\frac{W_{k}}{I_{k} / P} \frac{d\left(I_{k} / P\right)}{d W_{k}}$ is the marginal effect of the wage on the real income of households covered by union $k$, or the wage - real income effect and $\widehat{\lambda}_{k} \equiv-\frac{W_{k}}{L_{k}} \frac{d L_{k}}{d W_{k}}$, is the corresponding elasticity of labour demand, when unions perceive even a small influence on the aggregate wage.

Proposition 3 In the presence of $1<N<\infty$ influential price setters and $0<$ $K \leq N$ unions, hence for $0<\zeta \leq 1$, (i) The wage-real income elasticity $\left(\widehat{\xi}_{k}\right)$, can be decomposed into three effects, (a) the wage-real gains from employment effect, (b) the wage-real money effect and (c) the wage-real profit effect.

Proof. This follows directly from the derivation of $\widehat{\xi}_{k}$, (see Appendix B).

profit sharing the effect of the wage on the profits held by each union members, usually enters through wage bargaining between unions and employers over wages and profits (see Holmund 1990, Georges, 1998). Alternatively, some models of profit sharing prefer to incorporate this wage-profit effect by adding some share of profits to the compensation of each worker and then choose the optimal wage -and often the optimal profit share- according to a given utility for the union, (Georges 1998). Secondly, unlike most of the profit sharing literature, the results in this model are independent to the portion of the profit sharing, because here all profits are distributed equally to all household and households comprise both producers and workers. Thirdly, influential unions affect aggregate nominal variables and as we show below this introduces an additional effect in wage setting. 
At the symmetric Nash equilibrium the wage choice of each union is, ${ }^{11}$

$$
\begin{aligned}
\widehat{W} & =\frac{A}{\widehat{\mu}}\left(\frac{1}{K M_{0} P^{* \phi_{R}}}\left(\frac{\theta \widehat{\lambda}}{\widetilde{\gamma}_{\theta} A^{\theta \widehat{\xi}}}\right)^{\frac{1}{(\theta-1)}}\right)^{\frac{1}{1-\phi_{R}}}, \\
\widehat{\lambda} & =\sigma-\zeta\left(\sigma-1+\phi_{R}\right), \\
\widehat{\xi} & =\frac{\gamma}{\widehat{\mu}}(\widehat{\lambda}-1+\zeta)+\zeta(1-\gamma)\left(1-\phi_{R}\right)+\frac{\zeta \gamma(\widehat{\mu}-1)}{\widehat{\mu}}\left(1-\phi_{R}\right),
\end{aligned}
$$

where $\widetilde{\gamma}_{\theta}=\widetilde{\gamma}(1-\gamma)^{\theta-1} \gamma^{-\theta}$ is a constant and $\widehat{\lambda}, \widehat{\mu}$, and $\widehat{\xi}$, are the symmetric equilibrium values of the labour elasticity of demand, the mark-up and the wage-real income effect, respectively. The last two terms in $\widehat{\xi}$ corresponds to the the non-wage income effect (i.e. the wage-real money and the wage-real profit effects respectively). This effect, which is novel to the recent literature of large monopolistic price and wage setters, is shown to introduce a new potential channel through which monopolistic institutions can interact with monetary policy. Note that complete wage decentralization, $K=N$, combined with $N \rightarrow \infty$, results in $\widehat{\lambda} \rightarrow \lambda=\sigma$ and $\widehat{\xi} \rightarrow \xi=\frac{\gamma}{\mu}(\lambda-1)$, which are typical elasticities of the standard approximation case; in this case $d \widehat{\lambda} / d \phi_{R}=0$, and $\widehat{d \xi} / d \phi_{R}=0 .{ }^{12}$

Proposition 4 In the presence of $1<N<\infty$ influential price setters and $0<K \leq N$ unions, hence for $0<\zeta \leq 1$, (i) $d \widehat{\lambda} / d \phi_{R}<0$, hence monetary accommodation results in a lower labour elasticity of demand than that implied

\footnotetext{
${ }^{11}$ For a detailed derivation of $\widehat{\xi}$ see Appendix B.

12 Note that in this paper, as with most of this literature, we are concerned with short run monetary policy responses, and therefore from this point of view the assumption of a fixed number of firms and unions is an appropriated one. Although this is beyond the scope of this paper, in a long run analysis, as more firms enter the market, monopolistic power and profits should theoretically be driven to zero, and so not only the wage-real profit effect but the whole concept of influential monopolistic price setters would be expected to be eliminated.
} 
by the standard approximation, $(K=N=\infty)$ hence $\widehat{\lambda}_{A}<\lambda$; (ii) For values $\phi_{T}<-(\sigma-1)$, price targeting results in a higher labour elasticity of demand, than that implied by the standard approximation, $\widehat{\lambda}_{T}>\lambda$; (iii) The effect of monetary policy on the labour elasticity of demand is larger the higher is the degree of wage centralization, $\zeta$.

Proof. See Appendix C.

[ Table 2. The Effects of Monetary Policy and Wage Centralization on the Labour Demand Elasticity]

Table 2 demonstrates the effects of monetary policy and wage centralization on $\hat{\lambda}$, measured by $1-\hat{\lambda} / \lambda$ and so in relation to $\lambda$. Notice that the higher is the degree of wage centralization (i.e. the lower is $K$ ), the larger becomes the difference in these elasticities .With 30 large unions covering 1000 large firms, for example, less than full monetary accommodation $\left(\phi_{R}=0.9\right)$ can result in a $3.3 \%$ reduction of $\widehat{\lambda}$, in relation to that implied by the standard approximation $\lambda$; yet as we show below even small changes in these elasticities can have large real effects.

Proposition 5 In the presence of $1<N<\infty$ influential price setters and $0<K \leq N$ unions, hence for $0<\zeta \leq 1$, (i) for $\phi_{R}<1$, the wage-real income elasticity, $(\widehat{\xi})$, is higher than that implied by models where large monopolistic unions neglect the effect of wages on their members' non-wage real income; (ii) full monetary accommodation, $\left(\phi_{R}=1\right)$, eliminates unions' concern about their members' non-wage real income.

Proof. See Appendix C. 
Therefore intuitively, a higher $\widehat{\xi}$ is implied when unions take into account their members' non-wage real income. However, because full monetary accommodation fully compensates the effects of aggregate demand on real money transfers and real profits, $\phi_{R}=1$ eliminates such effect from wage setting and this reduces $\widehat{\xi}$.

Proposition 6 In the presence of $1<N<\infty$ influential price setters and $0<K \leq N$ unions, hence for $0<\zeta \leq 1$, (i) monetary accommodation reduces the wage - real income elasticity, $\widehat{d} \widehat{\xi} / \phi_{R}<0$; (ii) price targeting results in a higher wage - real income elasticity than monetary accommodation, $\widehat{\xi}_{T}>\widehat{\xi}_{A}$; (iii) $\widehat{\xi} \lesseqgtr \xi$, yet there is a unique value $\phi_{R}^{*}$ that makes the wage - real income elasticity equal to that implied by the standard approximation, $\widehat{\xi}=\xi$.

Proof. See Appendix C.

[ Table 3. The Effects of Monetary Policy and Wage Centralization on the

$$
\text { Wage - Real Income Elasticity] }
$$

\subsection{Influential Monopolistic Agents and Real Effects}

Equilibrium employment is given by substituting the interaction of the two symmetric Nash equilibria in price and wage setting into the demand for employment at the symmetric equilibrium. The demand for employment covered by union $k$ is,

$$
L_{k}=\frac{\gamma M_{0}}{(1-\gamma) K\left(A P^{*}\right)^{\phi_{R}}}\left(W_{k} \widehat{\mu}\right)^{-\left(1-\phi_{R}\right)} .
$$

Employment is negatively related to the wage; however, as expected, for a fixed wage employment is increasing in the degree of monetary accommodation 
$\left(0<\phi_{A} \leq 1,\right)$ and decreasing the higher is the weight on price targeting $\left(\phi_{T}<\right.$ 0). Substituting equation (19), into equation (20) and aggregating over all industries $i=1,2 \ldots N$, using $L=\sum_{i=1}^{N} L_{i}=\sum_{k=1}^{K} L_{k}$ and $Y=A L$ we derive the symmetric equilibrium output,

$$
\widehat{Y}=\left(\frac{\bar{\gamma} A^{\theta} \widehat{\xi}}{\theta \widehat{\lambda}}\right)^{\frac{1}{\theta-1}}
$$

where $\bar{\gamma}=\left(\frac{1-\gamma}{\gamma}\right)^{1-\gamma}$. From equation (21) we can show that as $K=N \rightarrow \infty$, $\widehat{\xi} \rightarrow \xi, \widehat{\lambda} \rightarrow \lambda$ and $\widehat{Y} \rightarrow Y=\left(\frac{\bar{\gamma} A^{\theta} \xi}{\theta \lambda}\right)^{\frac{1}{\theta-1}}$. In this case, equilibrium output is shown to be invariant to the monetary policy parameter $\phi_{R}$, confirming the well-established result that in the absence of nominal rigidities money neutrality holds even in models of imperfect competition. ${ }^{13}$ Yet, in the presence of influential monopolistic competitors, a number of interesting implications arise as both $\widehat{\lambda}$ and $\widehat{\xi}$ depend on the central bank's policy parameter, $\phi_{R}$.

Proposition 7 In the presence of $1<N<\infty$ influential price setters and $0<K \leq N$ unions, hence for $0<\zeta \leq 1$, (i) price targeting increases equilibrium output; (ii) price targeting results in a higher equilibrium output than an accommodating monetary policy;

Proof. See in the Appendix C.

The intuition of these results follows directly from the effects we have shown in the above propositions. Price targeting increases the price elasticity of demand, $(\widehat{\varepsilon})$, the labour elasticity of demand, $(\widehat{\lambda})$ and the elasticity of the wage with respect to households' total real income $(\widehat{\xi}[\widehat{\lambda}])$. The first effect reduces the

\footnotetext{
${ }^{13}$ For a survey see Dixon and Rankin (1994).
} 
price mark-up whereas the latter two effects reduce the equilibrium wage. Both effects result in a higher equilibrium output under price targeting than monetary accommodation.

\section{Influential Competitors and Macroeconomic}

\section{Inefficiencies}

Because of the inefficiencies associated with monopolistic competition, the monopolistic equilibrium output is expected to be lower than the competitive equilibrium output. ${ }^{14}$ In this section we simulate the additional inefficiencies, $(\widetilde{Y})$, arising from influential competitors, in relation to the inefficiencies implied by the standard approximation. As with Blanchard and Kiyotaki (1987) we use as a measure of inefficiencies the proportional ratio of the two output equilibria, $\widetilde{Y} \equiv 1-\frac{\widehat{Y}}{Y} \cdot{ }^{15}$ This measure can also be used as an indicator of the appropriateness of the standard approximation; the closer is $|\widetilde{Y}|$ to zero the more robust is the standard approximation.

Using equation (21) and its counterpart of the standard approximation, $a d$ ditional inefficiencies are measured as,

$$
\widetilde{Y} \equiv 1-\frac{\widehat{Y}}{Y}=1-\left(\frac{\widehat{\xi} / \widehat{\lambda}}{\xi / \lambda}\right)^{\frac{1}{\theta-1}}
$$

\footnotetext{
${ }^{14}$ See Blanchard and Kiyotaki (1987). Also, Benassi et al (2002), examine the welfare implications of the CPI effect directly in relation to the size of $N$, (i.e. assuming an exogenous money supply, as in the standard literature).

${ }^{15} \mathrm{As}$ with the rest of the tables, for expositional convenience we subtract this ratio from one.
} 
Proposition 8 In the presence of $1<N<\infty$ influential price setters and $0<$ $K \leq N$ unions, hence for $0<\zeta \leq 1$, (i) monetary accommodation feeds into the monopolistic power of influential competitors and raises production inefficiencies whereas price targeting reduces them; (ii) Strict price targeting, $\left(\phi_{T} \rightarrow-\infty\right)$, fully eliminates the power of influential firms and unions to generate real effects through their effect on nominal aggregates.

Proof. See in the Appendix C.

Strict price targeting results in,

$$
\widehat{P}=P=P^{*} ; \quad M / P=M_{0} / P^{*} \quad \text { and } \quad \widehat{Y}=Y=\left(\frac{\gamma}{1-\gamma}\right) \frac{M_{0}}{P^{*}}
$$

Therefore strict price targeting results in the same equilibrium output under both influential and non-influential competitors. In this case, equilibrium output is shown to be determined by exogenous factors, such as the level of the price target itself, $\left(P^{*}\right)$, the initial money stock in the economy $\left(M_{0}\right.$, a constant) and by the households' relative preferences for real consumption, $(\gamma)$, as opposed to real money balances, $(1-\gamma)$. Intuitively, because strict price targeting does not allow even the smallest deviation of the CPI from its fixed target, it neutralises any attempt of monopolistic competitors to affect aggregate demand through their influence on aggregate nominal variables and so it delivers the same equilibrium output, regardless the product or labour market structures.

Proposition 9 In the presence of $1<N<\infty$ influential price setters and $0<$ $K \leq N$ unions, hence for $0<\zeta \leq 1$, numerical estimations show that even in the 
presence of influential monopolistic competitors, the standard approximation, $K=N \rightarrow \infty$, is a good one, provided that (a) more than a few hundreds of influential firms operate in any time in the economy and (b) labour markets are decentralized or wage centralization is very low.

Proof. See numerical simulation in Tables 1, 2,3 and 4 .

[ Table 4. Monetary Policy, Influential Competitors and Inefficiencies ]

Turning to the other parameters in the model, in general the lower is $\gamma$ the more important becomes the role of monetary policy and since the latter

affects $\widehat{Y}$ but not $Y$, the lower is $\gamma$, the higher becomes $|\widetilde{Y}|$. However, the latter ratio is moderated the higher is the gross substitutability between goods (i.e. the higher is $\sigma$ ). The value $\theta-1$ is the elasticity of marginal disutility of labour. If $\theta$ is close to unity the marginal disutility of labour is constant. In general, lower values of $\theta$ raise the value of $|\widetilde{Y}|$.

\section{Concluding Remarks}

Governments across the industrial world will frequently pursue talks with influential industry and union representatives. This is particularly true for periods for which governments are keen to pursue an anti-inflationary policy. If large industries or unions can pose no influence on aggregate nominal variables, there would be no call for price or wage restraints by their behalf. This is the rationale of the recent literature that studies potential interactions between monetary policy and large monopolistic price and wage setters. 
Building on this literature this paper shows that in economies where large industries or unions perceive even a very small influence on aggregate nominal variables, price targeting results in a higher equilibrium output than an accommodating monetary policy. This is because price targeting raises, whereas accommodation reduces, the price elasticity of demand, the labour elasticity of demand and the elasticity of the wage with respect to households' total real income. The latter effect, introduces a new source through which influential unions can interact with aggregate demand and although it moderates earlier results in the literature, it provides further support for price targeting; the latter is shown to raise equilibrium output and reduce the macroeconomic inefficiencies associated with powerful monopolistic competitors.

As the paper shows, the most potential source of such real effects is expected to be the structure of labour markets and particularly the degree of wage centralization. Indeed, our results extend their support to recent work that suggests that the size of such real effects is crucially determined by the structure of wage bargaining in combination with central bank preferences (i.e. Iversen 1998, Guzzo and Velasco 1999, Cukierman and Lippi 1999, Coricelli Cukierman and Dalmazzo 2000, 2004, Holden 2003 Lippi 2003). Similarly, our results also support studies that attempt to explain endogenously the structure of wage bargaining by focusing on how the degree of monetary accommodation in different countries may determine the gains from coordination in wage setting, (i.e. Holden, 2005) or the flexibility in wage contracts (Groth and Johansson 2002). They may, for example, help explain why countries with a traditionally strict monetary stance or inflation targeting such as the US, and Canada and more recently the UK, have had low centralization in wage setting, whereas 
Italy, Norway and other Scandinavian countries where monetary policy has been more passive, have had higher degrees of wage centralization.

Finally, the paper shows that even in models of influential price and wage setters the standard approximation, of neglecting the effects of individual price and wage setters, is a good one, provided that in the economy considered, (a) more than a few hundreds of influential firms operate at any time, and more importantly (b) labour markets are decentralized or wage centralization is very low.

\section{References}

Alogoskoufis, George and Ron P. Smith, 1991, "The Phillips Curve, the Persistence of Inflation, and the Lucas Critique: Evidence from Exchange-Rate Regimes", American Economic Review, Vol. 81 (December), pp. 1254-75.

D'Aspremont Claude, Ferreira R.D.S, and Gerard-Varet L-A., 1996, "On the Dixit-Stiglitz Model of Monopolistic Competition" American Economic Review Vol. 86(3), 623-629.

Benassi, Corrado, Alessandra Chirco and Caterina Colombo, 2002. "The Price Index Effect and Macroeconomic Inefficiency", Récherches Economiques de Louvain, Vol. 68, n 3, pp. 385-394.

Blanchard, Oliver Jean and Kiyotaki, Nobuhiro, 1987. "Monopolistic Competition and the Effects of Aggregate Demand.” American Economic Review, $77(4), 647-66$.

Bratsiotis, George J., and Christopher Martin, 1999. "Stabilisation, Policy Targets and Unemployment in Imperfectly Competitive Economies", 
Scandinavian Journal of Economics, 101(2), 241-256.

Calmfors, Lars and H. Horn, 1985. "Classical Unemployment, Accommodation Policies, and the Adjustment of Real Wages", Scandinavian Journal of Economics, 87, 2 .

Coricelli, Fabrizio, Alex Cukierman and Alberto Dalmazzo, 2000. "Monetary Institution, Monopolistic Competition, Unionized Labor Markets and Economic Performance", Discussion Paper Series 2407, Centre for Economic Policy Research, London (CEPR), January .(Forthcoming: Scandinavian Journal of Economics).

Coricelli, Fabrizio, Alex Cukierman and Alberto Dalmazzo, 2004, "Economic performance and Stabilization Policy in a Monetary Union with Imperfect Labor and Goods Markets", in:European Monetary Integration, edited by H.W.Sinn, M. Widgren and M. Koethenbuerger, MIT Press.

Cukierman, Alex and Francesco Lippi (1999), "Central Bank Independence, Centralization of Wage Bargaining, Inflation and Unemployment: Theory and Some Evidence", European Economic Review 43, 1395 - 1434.

Dixit, Avinash K. and Stiglitz, Joseph E., 1977. "Monopolistic Competition and Optimum Product Diversity." American Economic Review, , 67(3), 297-308.

Dixon, Huw, and Rankin, Neil., 1994. "Imperfect Competition Macroeconomics: A Survey", Oxford Economic Papers, 46, 171-199.

Driffill, John. 1985, Macroeconomic Stabilization Policy and Union Behaviour, Scandinavian Journal of Economics, Vol. 87, No 2. 
Georges, Christophre, 1998. "Profit shares Bargaining and Unemployment", Economic Inquiry, Vol. XXXVI, 286-291.

Groth, Charlotta and Åsa Johansson, 2002. "Bargaining Structure and Nominal Wage Flexibility", Seminar Papers 709, Stockholm University, Institute for International Economic Studies.

Guzzo, Vincenzo and Andrés Velasco, (1999). "The Case for a Populist Central Banker", European Economic Review 43, 1317 - 1344.

Holden, Steinar, 2003. "Wage setting under different monetary regimes", Economica, vol 70, no 2, pp.251-265.

Holden, Steinar, 2005. "Monetary Regime and the Co-ordination of Wage Setting" European Economic Review, 49, pp.833-843.

Holmlund, Bertil, 1990. "Profit sharing, Wage Bargaining and Employment", Economic Inquiry, Vol. XXVIII, 257-268.

Iversen, Torben, 1998. "Wage Bargaining, Central Bank Independence, and the Real Effects of Money", International Organization, MIT Press, vol. 52(3), pages 469-504.

Iversen Torben and David Soskice, 2000. "The Non Neutrality of Monetary Policy with Large Price Or Wage Setters", 115, (1), 265-84.

Knell, Markus, 2002. "Wage Formation in Open Economies and the Role of Monetary and Wage Setting Institutions", Oesterreichische Nationalbank, Working Paper 63, May 2002.

Lippi, Francesco, 2003. "Strategic Monetary Policy with Non-Atomistic Wage Setters, Review of Economic Studies 70, 909-919. 
Taylor, John, B., 1979. "Staggered Wages in a Macro Model", American Economic Review, Vol. 69, pp. 108-113.

Taylor, John, B., 1980. "Aggregate Dynamics and Staggered Contracts", Journal of Political Economy, Vol. 88, pp. 1-23.

Vartiainen, Juhana, 2002. "Relative wages in Monetary Union and Floating". Scandinavian Journal of Economics 104, 277-288.

Yang, Xiaokai and Heijdra, Ben J., 1993. "Monopolistic Competition and Optimum Product Diversity: Comment" American Economic Review, 83(1), 295-301.

\section{APPENDIX}

\section{Appendix A.}

\section{Derivation of $\widehat{\varepsilon}$}

From equation (10), (1) and (4) and relaxing the assumption $\partial P / \partial P_{i}=0$, the price elasticity of demand is

$$
\widehat{\varepsilon}_{i}=-\frac{P_{i}}{Y_{i}} \frac{d Y_{i}}{d P_{i}}=-\frac{P_{i}}{Y_{i}} \frac{\partial Y_{i}}{\partial P_{i}}-\left(\frac{P}{Y_{i}} \frac{\partial Y_{i}}{\partial P}+\frac{M}{Y_{i}} \frac{\partial Y_{i}}{\partial M} \frac{P}{M} \frac{\partial M}{\partial P}\right)\left(\frac{P_{i}}{P} \frac{\partial P}{\partial P_{i}}\right) .
$$

From equation (10) the direct effect is $\frac{P_{i}}{Y_{i}} \frac{\partial Y_{i}}{\partial P_{i}}=\sigma$ and from equation (4), $\frac{\partial P}{\partial P_{i}}=P_{i}^{-\sigma}\left(P / \sum_{j=1}^{N} P_{j}^{1-\sigma}\right)$, where $i \in j$, hence,

$$
\frac{P_{i}}{P} \frac{\partial P}{\partial P_{i}}=\frac{P_{i}^{1-\sigma}}{\sum_{j=1}^{N} P_{j}^{1-\sigma}}, \quad i \in j
$$

or dividing through by $M_{H}^{1-\sigma}$ and using the money market equilibrium condi- 
tion, $M_{H}=M$, results in,

$$
S_{i}=\frac{\left(P_{i} / M\right)^{1-\sigma}}{\sum_{j=1}^{N}\left(P_{j} / M\right)^{1-\sigma}}, \quad i \in j .
$$

From equation (1), $\frac{P}{M} \frac{\partial M}{\partial P}=\frac{P}{m M_{0}} \frac{\partial m M_{0}}{\partial P}=\frac{P}{m} \frac{\partial m}{\partial P}$, where $m=\left(\frac{P}{P^{*}}\right)^{\phi_{R}} ; \frac{\partial m}{\partial P}=$ $\phi_{R}\left(\frac{P^{\phi_{R}-1}}{P^{*}}\right)$ and therefore,

$$
\frac{P}{M} \frac{\partial M}{\partial P}=\phi_{R}
$$

From equation (10), $\frac{\partial Y_{i}}{\partial P}=\frac{Y_{i}(\sigma-1)}{P}$ and therefore,

$$
\frac{P}{Y_{i}} \frac{\partial Y_{i}}{\partial P}=\sigma-1
$$

Substituting equations (A2)-(A5) into (A10) results in equation (15),

$$
\widehat{\varepsilon}_{i}=\sigma-\psi_{i}, \quad \psi_{i}=\left(\sigma-1+\phi_{R}\right) S_{i} .
$$

At the symmetric equilibrium $P_{i}=P_{j}=P$ and so equation (A3) simplifies to, $S_{i} \rightarrow S=1 / N$, which results in equation (16).

$$
\widehat{\varepsilon}=\sigma-\psi, \quad \psi=\left(\sigma-1+\phi_{R}\right) / N \text {. }
$$

\section{Appendix B.}

\section{Derivation of $\widehat{\lambda}$ and $\widehat{\xi}$}

If unions perceive even a small influence on the aggregate price level, $\widehat{\xi}_{k}$ is,

$$
\widehat{\xi}_{k}=-\frac{W_{k}}{\left(I_{k} / P\right)} \frac{d\left(I_{k}\left[W_{k}\right] / P\left[W_{k}\right]\right)}{d W_{k}} .
$$


From equations (4) (5) and (14) the latter effect is

$$
\frac{d\left(I_{k}\left[W_{k}\right] / P\left[W_{k}\right]\right)}{d W_{k}}=\frac{d}{d W_{k}}\left(\frac{W_{k} L_{k}}{P}+\frac{m M_{k, 0}}{P}+\sum_{j=1}^{N} \frac{V_{k j}}{P}\right) .
$$

Equation (B2) shows wage setting by influential unions to take three effects into account: the wage-real gains from employment effect (the first term in $\mathrm{B} 2)$; the wage-real money effect (the second term) and the wage-real profit effect (the last term) .From equations (1), (4), (5) (7), (12) (13) (14), we have $P=P\left[W_{k}, \ldots\right] ; m=m\left[P\left[W_{k}, \ldots\right]\right] ; L_{k}=L_{k}\left[W_{k}, P\left[W_{k} \ldots\right], M\left[P\left[W_{k} \ldots\right]\right]\right]$; $L_{z}=L_{z}\left[\ldots, P\left[W_{k}, \ldots\right], M\left[P\left[W_{k}, \ldots\right]\right]\right]$, for $z \neq k$ and $V_{k j}=V_{k j}\left[W_{k}, L_{k}(\cdot), L_{z}(\cdot)\right]$.

(a) The wage - real gains from employment effect

Using the price and employment of firms covered by unions $k, P_{k}=\frac{\mu W_{k}}{A}$ and $L_{k}=\frac{\gamma}{(1-\gamma) K A}\left(\frac{M}{P}\right)\left(\frac{P_{k}}{P}\right)^{-\sigma}$ we obtain,

$$
\begin{aligned}
\frac{W_{k}}{P} \frac{d L_{k}}{d W_{k}}= & \frac{L_{k}}{P}\left(\frac{W_{k}}{L_{k}} \frac{\partial L_{k}}{\partial W_{k}}+\frac{W_{k}}{P} \frac{\partial P}{\partial W_{k}}\left(\frac{P}{L_{k}} \frac{\partial L_{k}}{\partial P}+\frac{M}{L_{k}} \frac{\partial L_{k}}{\partial M} \frac{P}{M} \frac{\partial M}{\partial P}\right)\right) \\
& +\frac{L_{k}}{P}\left(1-\frac{W_{k}}{P} \frac{\partial P}{\partial W_{k}}\right) .
\end{aligned}
$$

Using the definition of wage centralization, $\zeta=\frac{W_{k}}{P} \frac{d P}{d W_{k}}$, and the definition of the labour elasticity of demand, $\widehat{\lambda}_{k} \equiv-\frac{W_{k}}{L_{k}} \frac{d L_{k}}{d W_{k}}$, equation (B3) is,

$$
\begin{aligned}
\frac{W_{k}}{P} \frac{d L_{k}}{d W_{k}} & =-\frac{L_{k}}{P}\left(\widehat{\lambda}_{k}-1+\zeta\right) \\
\text { where } \widehat{\lambda}_{k} & \equiv-\left(\frac{W_{k}}{L_{k}} \frac{\partial L_{k}}{\partial W_{k}}+\frac{W_{k}}{P} \frac{\partial P}{\partial W_{k}}\left(\frac{P}{L_{k}} \frac{\partial L_{k}}{\partial P}+\frac{M}{L_{k}} \frac{\partial L_{k}}{\partial M} \frac{P}{M} \frac{\partial M}{\partial P}\right)\right) .
\end{aligned}
$$

(b) The wage - real money income effect

The effect of wages on money transfers comes from the fact that the policy 
rule is endogenous to prices and so through their effect on the CPI, wage setting activates the policy rule. Denoting $M_{k}$ the money transfers of households covered by union $k$ we obtain,

$$
\frac{d}{d W_{k}}\left(\frac{m M_{k, 0}}{P}\right)=\frac{m M_{k, 0}}{P W_{k}} \frac{W_{k}}{P} \frac{d P}{d W_{k}}\left(\frac{P}{m M_{k, 0}} \frac{d m M_{k, 0}}{d P}-1\right) .
$$

Using, $\frac{W_{k}}{P} \frac{d P}{d W_{k}}=\zeta$ and $\frac{P}{m} \frac{\partial m}{\partial P}=\phi_{R}$, we obtain,

$$
\frac{d}{d W_{k}}\left(\frac{m M_{k, 0}}{P}\right)=-\frac{m M_{k, 0}}{P W_{k}} \zeta\left(1-\phi_{R}\right) .
$$

(c) The wage - real profit effect

Given that all households hold an equal share of profits from all industries (see equation 5), and that each firm $j=1,2 \ldots . N$, is represented by a household, the real profits from the shares of each firm $j$, accruing to each household $h$ are, $V_{h j}=V_{j} / N P$, or in terms of real profits accruing to households covered by union $k, V_{k j}=V_{k} / K P$. Given symmetry, the total real profits accruing to the members of each union $k$, is simply $\sum_{k=1}^{K} \frac{V_{k}}{K P}=\frac{V_{1}+V_{2}+\ldots V_{K}}{K P}$

Using this and equations (11) - (14) we obtain,

$$
\sum_{k=1}^{K} \frac{V_{k}}{K P}=\frac{L_{k} W_{k}}{K P}\left(\mu_{k}-1\right)+\frac{1}{K} \sum_{\substack{z=1 \\ z \neq k}}^{K-1} \frac{L_{z} W_{z}}{P}\left(\mu_{z}-1\right) .
$$

Equation (B8) shows that the assumption of an economy-wide employee share ownership results in the household's total profit real income being a function not only of the profits of the firms covered by its own union, but also of all other firms, covered by other unions. In addition, the fact that influen- 
tial unions may have an effect on the average wage, hence on the CPI, results in the wage covered by union $k,\left(W_{k}\right)$, affecting the real profits of its member's through, (a) the real wage and the demand for employment and of its own members $W_{k} / P=W_{k} / P\left[W_{k} \ldots\right]$ and $L_{k}=L_{k}\left[W_{k} / P\left[W_{k} \ldots\right]\right]$ and (b) the real wage and the demand for employment covered by other unions $z$, since $W_{z} / P=W_{z} / P\left[W_{k} \ldots\right]$. and $L_{z}=L_{z}\left[W_{z} / P\left[W_{k} \ldots\right]\right]$.

From B8, the total wage effect on the household's real profits is,

$\frac{d}{d W_{k}}\left(\sum_{j=1}^{N} V_{k j} / P\right)=-\frac{L_{k}\left(\widehat{\mu}_{k}-1\right)}{K P}\left(\widehat{\lambda}_{k}-1+\zeta\right)+\sum_{\substack{z=1 \\ z \neq k}}^{K-1} \frac{L_{z} W_{z}\left(\widehat{\mu}_{z}-1\right)}{K P W_{k}}\left(\widehat{\lambda}_{z k}-\zeta\right)$.

where $\widehat{\lambda}_{k}$ and $\zeta$ are defined above and $\widehat{\lambda}_{z k}=\frac{W_{k}}{L_{z}} \frac{d L_{z}}{d W_{k}}$ is the cross wage elasticity of labour demand, $\widehat{\lambda}_{j i}=\frac{W_{i}}{P} \frac{d P}{d W_{i}}\left(\frac{P}{L_{j}} \frac{d L_{j}}{d P}+\frac{M}{L_{j}} \frac{d L_{j}}{d M} \frac{P}{M} \frac{d M}{d P}\right)$

The total wage - real income effect is obtained by substituting the effects (B5) (B7) and (B9), into (B2),

$$
\begin{aligned}
\frac{d\left(I_{k} / P\right)}{d W_{k}}= & -\frac{L_{k}}{P}\left(\widehat{\lambda}_{k}-1+\zeta\right)-\frac{m M_{k, 0}}{P W_{k}} \zeta\left(1-\phi_{R}\right)-\frac{L_{k}\left(\widehat{\mu}_{k}-1\right)}{K P}\left(\widehat{\lambda}_{k}-1+\zeta\right) \\
& +\sum_{\substack{z=1 \\
z \neq k}}^{K-1} \frac{L_{z} W_{z}\left(\widehat{\mu}_{z}-1\right)}{K P W_{k}}\left(\widehat{\lambda}_{z k}-\zeta\right) .
\end{aligned}
$$

Substituting (B10) into (B1) we obtain,

$$
\begin{aligned}
\widehat{\xi}_{k}= & \frac{W_{k} L_{k}}{I_{k}}\left(\widehat{\lambda}_{k}-1+\zeta\right)+\frac{m M_{k, 0}}{I_{k}} \zeta\left(1-\phi_{R}\right)+\frac{W_{k} L_{k}\left(\widehat{\mu}_{k}-1\right)}{K I_{k}}\left(\widehat{\lambda}_{k}-1+\zeta\right) \\
& -\sum_{\substack{z=1 \\
z \neq k}}^{K-1} \frac{W_{z} L_{z}\left(\widehat{\mu}_{z}-1\right)}{K I_{k}}\left(\widehat{\lambda}_{z k}-\zeta\right)
\end{aligned}
$$

At the symmetric equilibrium, assuming $W_{k}=W_{z}=W, P_{i}=P, \mu_{k}=$ 
$\mu_{z}=\mu$ we obtain, $\widehat{\lambda}_{k}=\widehat{\lambda}=\sigma-\zeta\left(\sigma-1+\phi_{R}\right)$, where $\zeta=1 / K ; \widehat{\lambda}_{z k}=$ $\zeta\left(\sigma-1+\phi_{R}\right) \lessgtr 0 ; \quad \frac{L W}{I_{h i}}=\frac{\gamma}{\hat{\mu}}$. From equation (7), $I_{k}=\frac{M_{k}}{1-\gamma}$, using this we obtain, $\frac{m M_{k, 0}}{I_{k}}=\frac{(1-\gamma) m M_{k, 0}}{M_{k}}$ and using the definition of aggregate money equilibrium $M=\sum_{h=1}^{N} M_{h}=\sum_{k=1}^{K} M_{k}$, and the fact that $M_{0} / M=1 / m$ we obtain $\frac{m M_{k, 0}}{I_{k}}=1-\gamma$. Substituting these into (B11) we obtain $\widehat{\xi}$ as given in equation (19),

$$
\begin{aligned}
\widehat{\xi}= & \frac{\gamma}{\widehat{\mu}}(\widehat{\lambda}-1+\zeta)+\zeta(1-\gamma)\left(1-\phi_{R}\right)+\frac{\gamma}{\widehat{\mu}} \frac{(\widehat{\mu}-1)}{K}(\widehat{\lambda}-1+\zeta) \\
& -\sum_{\substack{z=1 \\
z \neq k}}^{K-1} \frac{\gamma}{\widehat{\mu}} \frac{(\widehat{\mu}-1)}{K}\left(\widehat{\lambda}_{z k}-\zeta\right) \\
= & \frac{\gamma}{\widehat{\mu}}(\widehat{\lambda}-1+\zeta)+\zeta(1-\gamma)\left(1-\phi_{R}\right)+\frac{\zeta \gamma(\widehat{\mu}-1)}{\widehat{\mu}}\left(1-\phi_{R}\right)
\end{aligned}
$$

\section{Appendix C.}

Proof of Proposition 1. (i) For $\widehat{\mu}=\left(1-\frac{1}{\bar{\varepsilon}}\right)^{-1}>0$ we require that $\widehat{\varepsilon}>1 .{ }^{16}$ We can show that any value of $\sigma>1+\frac{\phi_{R}}{N-1}$, satisfies $\widehat{\varepsilon}>1$ and hence $\widehat{\mu}>0 . \phi_{R} \leq 1$ and so even in the case of full monetary accommodation, $\left(\phi_{R}=1\right)$, any values of $N \geq 2$ and $\sigma>2$, satisfy $\widehat{\varepsilon}>1$. From equation (16), $\widehat{\varepsilon}=\sigma-\psi$ and $\psi=\left(\sigma-1+\phi_{R}\right) / N$. From this we can formally show that, $d \widehat{\varepsilon} / d \phi_{R}=-d \psi / d \phi_{R}=-1 / N<0$. Since $\widehat{\varepsilon}$ is a continuous and monotonic function of $\phi_{R}$, where $\phi_{R} \leq 1$, higher monetary accommodation, (positive values values of $\phi_{R}$ ) increases $\psi$, whereas price targeting (i.e. negative values values of $\phi_{R}$ ) decrease $\psi$. Since, $\psi_{T}<\psi_{A}$, we also obtain $\widehat{\varepsilon}_{T}>\widehat{\varepsilon}_{A}$ and given that $\widehat{\mu}_{T}=\left(1-\frac{1}{\hat{\varepsilon}_{T}}\right)^{-1}$ and $\widehat{\mu}_{A}=\left(1-\frac{1}{\varepsilon_{A}}\right)^{-1}, \widehat{\mu}_{T}<\widehat{\mu}_{A}$, hence for a given wage, $\widehat{P}_{T}<\widehat{P}_{A}$.

\footnotetext{
${ }^{16}$ Note that $\widehat{\varepsilon}>1$ is also required for satisfying second order conditions.
} 
Proof of Proposition 2. From equation (16), we can show that, (i) for $\sigma>1$ any positive value of $\phi_{R}>0$ satisfies $\sigma>\sigma-\left(\sigma-1+\phi_{R}\right) / N$ . Since $0<\phi_{A} \leq 1$, then $\varepsilon=\sigma>\widehat{\varepsilon}_{A}=\sigma-\left(\sigma-1+\phi_{A}\right) / N$ and so $\widehat{\mu}_{A}=\left(1-\frac{1}{\widehat{\varepsilon}_{A}}\right)^{-1}>\mu=\left(1-\frac{1}{\varepsilon}\right)^{-1}$, hence for a given wage, $\widehat{P}_{A}>P$; (ii) for $\phi_{T}<-(\sigma-1)$, price targeting results in $\varepsilon=\sigma<\widehat{\varepsilon}_{T}=\sigma-\left(\sigma-1+\phi_{T}\right) / N$, hence for a given wage, $\widehat{\mu}_{T}<\mu$ and $\widehat{P}_{T}<P$.

Proof of Proposition 4. From equation (19) and for values, $\sigma>1$ and $0<\zeta \leq 1$, we can show that (i) $d \widehat{\lambda} / d \phi_{R}=-\zeta<0$ and hence any positive value of $\phi_{R}>0$ satisfies $\lambda=\sigma>\hat{\lambda}=\sigma-\zeta\left(\sigma-1+\phi_{R}\right)$. Since $0<\phi_{A} \leq 1$ it also follows that $\widehat{\lambda}_{A}<\lambda$.; (ii) for values of $\phi_{T}<-(\sigma-1)$, price targeting results in $\widehat{\lambda}_{T}>\lambda$; (iii) $\left|d \widehat{\lambda} / d \phi_{R}\right|=\zeta$, hence the effect of monetary policy on the labour elasticity of demand is larger the higher is the degree of wage centralization, $\zeta$.

Proof of Proposition 5. From equation (19). and for values $0<N<\infty$, $0<\zeta \leq 1$ and $\sigma>1$ we can show that (i) for $\phi_{R}<1$, the last term in the definition of $\widehat{\xi}$, is positive, $\frac{\zeta \gamma(\widehat{\mu}-1)}{\widehat{\mu}}\left(1-\phi_{R}\right)>0$ hence the proposition is true; (ii) As $\phi_{R} \rightarrow 1$, the second and third terms in equation (19) are eliminated, reducing $\widehat{\xi}$ to the same value as that implied in models where large monopolistic competitors neglect the non-wage income effect.

Proof of Proposition 6. For values $1<N<\infty, 0<\zeta \leq 1$ and $\sigma>1$ we obtain, (i) $d \widehat{\xi} / \phi_{R}=-\left(\zeta+\frac{N \gamma(1-\zeta)(\sigma-1)}{\left(\sigma(N-1)+1-\phi_{R}\right)^{2}}\right)<0$; (ii) Since $d \widehat{\xi} / \phi_{R}<0$ and $\widehat{\xi}$ is a continuous and monotonic function of $\phi_{R}$, where $\phi_{R} \leq 1$, then it follows that price targeting $\left(\phi_{T}<0\right)$ increases $\widehat{\xi}$, whereas monetary accommodation $\left(0<\phi_{A} \leq 1\right)$ reduces $\widehat{\xi}$, hence $\widehat{\xi}_{T}>\widehat{\xi}_{A}$; (iii) With $\xi=\frac{\gamma}{\mu}(\lambda-1)$ being the total wage - real income effect in the standard approximation case, (i.e. $K=N$ 
$=\infty)$, then, $\xi-\widehat{\xi}=\frac{\gamma \sigma}{\mu}\left(\frac{N(1-\zeta)}{\sigma(N-1)+1-\phi_{R}}+\zeta-\frac{1}{\sigma}\right)-\zeta\left(1-\phi_{R}\right) \gtreqless 0$, determined largely by the values $\phi_{R}$, and $\zeta$. Formally, given the restriction $\phi_{R} \leq 1$, there is a unique critical value of monetary policy $\phi_{R}^{*}$ that results in $\xi=\widehat{\xi}$,

$$
\begin{aligned}
\phi_{R}^{*}= & 1+\frac{\sigma(N-1)}{2}-\frac{\gamma(\sigma \zeta-1)}{2 \zeta \mu} \\
& -\frac{1}{2 \zeta \mu} \sqrt{\gamma^{2}-2 \gamma \sigma \zeta\left(\gamma+\mu(2 N(\zeta-1)-1)+\sigma^{2} \zeta^{2}(\gamma+\mu(N-1))^{2}\right.}
\end{aligned}
$$

Values of $\phi_{R}$ above (below) $\phi_{R}^{*}$ result in $\widehat{\xi}<\xi(\widehat{\xi}>\xi)$. In general, the combination of higher monetary accommodation and high wage centralization, result in a higher $\xi-\widehat{\xi}>0$, whereas stricter price targeting with high values of $\zeta$ can result in $\xi-\widehat{\xi}<0$. Full monetary accommodation, $\phi_{R} \rightarrow 1$, results in $\xi-\widehat{\xi}=\frac{\gamma \sigma}{\mu}\left(\frac{N(1-\zeta)}{\sigma(N-1)}+\zeta-\frac{1}{\sigma}\right)>0$, and hence unambiguously in $\widehat{\xi}<\xi$. See also the simulation results in Table 3.

Proof of Proposition 7. (i) From propositions (4) and (6) we know that $\widehat{d \lambda} / d \phi_{R}<0$ and $\widehat{d \xi} / \phi_{R}<0$. and hence, from equation (21), for $\frac{d \widehat{Y}}{d \phi_{R}}<0$ we require that, $\left|\frac{d \widehat{\xi}}{d \phi_{R}}\right|>\left|\frac{d \widehat{\lambda}}{d \phi_{R}}\right|$. From propositions (4) and (6), $d \widehat{\lambda} / d \phi_{R}=-\zeta$ and $\widehat{d \xi} / \phi_{R}=-\left(\zeta+\frac{N \gamma(1-\zeta)(\sigma-1)}{\left(\sigma(N-1)+1-\phi_{R}\right)^{2}}\right)$, hence for $\sigma>1,1<N<\infty$, and $0<\zeta \leq 1,\left|\frac{d \widehat{\xi}}{d \phi_{R}}\right|>\left|\frac{d \widehat{\lambda}}{d \phi_{R}}\right|$ and therefore the above proposition is true, $\frac{d \widehat{Y}}{d \phi_{R}}<0$. Since $\widehat{Y}$ is a continuous and monotonic function of $\phi_{R}$, where $\phi_{R} \leq 1$, higher monetary accommodation, (positive values values of $\phi_{R}$ ) decrease $\widehat{Y}$, whereas price targeting (i.e. negative values values of $\phi_{R}$ ) increase $\widehat{Y}$; (ii) from this it also follows that $\widehat{Y}_{T}>\widehat{Y}_{A}$, hence the above proposition is true.

Proof of Proposition 8. (i) For monetary accommodation to increase inefficiencies we require that $d \widetilde{Y} / d \phi_{R}>0$ or that $d(\widehat{Y} / Y) / d \phi_{R}<0$. Since 
$Y$ is independent of $\phi_{R}$, we simply require that, $\frac{d \widehat{Y}}{d \phi_{R}}<0$, which is already shown in propositions (7) and (8). From these propositions, it follows that $d(\widehat{Y} / Y) / d \phi_{R}<0$ and so the above proposition is true; (ii) Strict price targeting, $(\phi \rightarrow-\infty)$, results in $\widehat{P}=P=P^{*}$. From equations $(1),(10)$ and $Y \equiv \sum_{j=1}^{N} Y_{j}$, aggregate demand at the symmetric equilibrium is given by $Y=\frac{\gamma}{1-\gamma}\left(\frac{M}{P}\right)$ and therefore strict price targeting results in $Y=\widehat{Y}=\frac{\gamma}{1-\gamma}\left(\frac{M_{0}}{P^{*}}\right)$, as shown in equation 23 .

Table 1. Monetary Policy and Price Mark-ups

\begin{tabular}{r|ccc|cccc}
\hline \multicolumn{1}{c}{ Monetary Accommodation } & \multicolumn{5}{c}{ Price Targeting } \\
\hline \multicolumn{1}{c}{$\phi_{R}$} & 0.3 & 0.5 & 0.9 & -0.7 & -1.5 & -2.5 & -7.0 \\
\hline \multicolumn{8}{c}{$1-(\hat{\varepsilon} / \varepsilon)$} \\
\hline$N=10$ & 0.0900 & 0.0928 & 0.0985 & 0.0757 & 0.0642 & 0.0500 & -0.0142 \\
30 & 0.0300 & 0.0309 & 0.0328 & 0.0252 & 0.0214 & 0.0166 & -0.0047 \\
100 & 0.0090 & 0.0092 & 0.0098 & 0.0075 & 0.0064 & 0.0050 & -0.0014 \\
500 & 0.0018 & 0.0019 & 0.0020 & 0.0015 & 0.0012 & 0.0010 & -0.0002 \\
1000 & 0.0009 & 0.0009 & 0.0010 & 0.0007 & 0.0006 & 0.0005 & -0.0001 \\
\hline \multicolumn{8}{c}{$1-(\hat{\mu} / \mu)$} \\
\hline$N=10$ & -0.0167 & -0.0173 & -0.0185 & -0.0138 & -0.0115 & -0.0088 & 0.0023 \\
30 & -0.0051 & -0.0053 & -0.0056 & -0.0043 & -0.0036 & -0.0028 & 0.0007 \\
100 & -0.0015 & -0.0016 & -0.0017 & -0.0012 & -0.0010 & -0.0008 & 0.0002 \\
500 & -0.0003 & -0.0003 & -0.0003 & -0.0002 & -0.0002 & -0.0001 & 0.0000 \\
1000 & 0.0001 & 0.0001 & 0.0002 & -0.0001 & -0.0001 & -0.0000 & 0.0000 \\
\hline
\end{tabular}


Table 2. Monetary Policy and Changes in the Labour Demand Elasticity

\begin{tabular}{|c|c|c|c|c|c|c|c|}
\hline \multicolumn{4}{|c|}{ Monetary Accommodation } & \multicolumn{4}{|c|}{ Price Targeting } \\
\hline$\phi_{R}$ & 0.3 & 0.5 & 0.9 & -0.7 & -1.5 & -2.5 & -7.0 \\
\hline \multicolumn{8}{|c|}{ Decentralized Labour Markets, $1-(\hat{\lambda} / \lambda)=1-(\hat{\varepsilon} / \varepsilon) \quad($ see Table 1$)$} \\
\hline \multicolumn{8}{|c|}{$1-(\hat{\lambda} / \lambda)-$ Varying Centralization } \\
\hline$N=1000, K=5$ & 0.1800 & 0.1857 & 0.1971 & 0.1514 & 0.1285 & 0.1000 & -0.0285 \\
\hline 10 & 0.0900 & 0.0928 & 0.0985 & 0.0757 & 0.0642 & 0.0200 & -0.0142 \\
\hline 30 & 0.0300 & 0.0309 & 0.0328 & 0.0252 & 0.0214 & 0.0166 & -0.0047 \\
\hline 120 & 0.0075 & 0.0077 & 0.0082 & 0.0063 & 0.0053 & 0.0041 & -0.0011 \\
\hline 350 & 0.0025 & 0.0026 & 0.0028 & 0.0021 & 0.0018 & 0.0014 & -0.0004 \\
\hline
\end{tabular}

Table 3. Monetary Policy and changes in the Wage - Real Income Elasticity

\begin{tabular}{|c|c|c|c|c|c|c|c|}
\hline \multicolumn{4}{|c|}{ Monetary Accommodation } & \multicolumn{4}{|c|}{ Price Targeting } \\
\hline$\phi_{R}$ & 0.3 & 0.5 & 0.9 & -0.7 & -1.5 & -2.5 & -7.0 \\
\hline \multicolumn{8}{|c|}{$1-(\xi / \xi)-$ Decentralized Labour Markets $(K=N)$} \\
\hline$K=N=10$ & $\begin{array}{c}0.0988 \\
(0.1033)^{*}\end{array}$ & $\begin{array}{c}0.1039 \\
(0.1071)\end{array}$ & $\begin{array}{c}0.1141 \\
(0.1147)\end{array}$ & $\begin{array}{c}0.0733 \\
(0.0843)\end{array}$ & $\begin{array}{c}0.0531 \\
(0.0691)\end{array}$ & $\begin{array}{c}0.0278 \\
(0.0500)\end{array}$ & $\begin{array}{c}-0.0851 \\
(-0.0357)\end{array}$ \\
\hline 30 & $\begin{array}{c}0.0329 \\
(0.0344)\end{array}$ & $\begin{array}{c}0.0346 \\
(0.0357)\end{array}$ & $\begin{array}{c}0.0380 \\
(0.0382)\end{array}$ & $\begin{array}{c}0.0245 \\
(0.0281)\end{array}$ & $\begin{array}{c}0.0177 \\
(0.0230)\end{array}$ & $\begin{array}{c}0.0093 \\
(0.0166)\end{array}$ & $\begin{array}{l}-0.0284 \\
(-0.0119)\end{array}$ \\
\hline 100 & $\begin{array}{c}0.0098 \\
(0.0103)\end{array}$ & $\begin{array}{c}0.0104 \\
(0.0107)\end{array}$ & $\begin{array}{c}0.0114 \\
(0.0114)\end{array}$ & $\begin{array}{c}0.0073 \\
(0.0084)\end{array}$ & $\begin{array}{c}0.0053 \\
(0.0069)\end{array}$ & $\begin{array}{c}0.0028 \\
(0.0050)\end{array}$ & $\begin{array}{l}-0.0085 \\
(-0.0035)\end{array}$ \\
\hline 500 & $\begin{array}{c}0.0019 \\
(0.0020)\end{array}$ & $\begin{array}{c}0.0020 \\
(0.0021)\end{array}$ & $\begin{array}{c}0.0022 \\
(0.0022)\end{array}$ & $\begin{array}{c}0.0014 \\
(0.0016)\end{array}$ & $\begin{array}{c}0.0010 \\
(0.0013)\end{array}$ & $\begin{array}{c}0.0005 \\
(0.0010)\end{array}$ & $\begin{array}{l}-0.0017 \\
(-0.0007)\end{array}$ \\
\hline 1000 & $\begin{array}{c}0.0009 \\
(0.0010) \\
\end{array}$ & $\begin{array}{c}0.0010 \\
(0.0011) \\
\end{array}$ & $\begin{array}{c}0.0011 \\
(0.0011)\end{array}$ & $\begin{array}{c}0.0007 \\
(0.0008) \\
\end{array}$ & $\begin{array}{c}0.0005 \\
(0.0006) \\
\end{array}$ & $\begin{array}{c}0.0002 \\
(0.0005) \\
\end{array}$ & $\begin{array}{c}-0.0008 \\
(-0.0003) \\
\end{array}$ \\
\hline \multicolumn{8}{|c|}{$1-(\hat{\xi} / \xi)-$ Varying Centralization $(\zeta=1 / K)$} \\
\hline \multirow{2}{*}{$\begin{array}{r}N=1000, K=5 \\
10\end{array}$} & $\begin{array}{c}0.1680 \\
(0.1767)\end{array}$ & $\begin{array}{c}0.1772 \\
(0.1834)\end{array}$ & $\begin{array}{c}0.1955 \\
(0.1967)\end{array}$ & $\begin{array}{c}0.1223 \\
(0.1434)\end{array}$ & $\begin{array}{c}0.0857 \\
(0.1167)\end{array}$ & $\begin{array}{c}0.0399 \\
(0.0834)\end{array}$ & $\begin{array}{c}-0.1660 \\
(-0.0666)\end{array}$ \\
\hline & $\begin{array}{c}0.0841 \\
(0.0884)\end{array}$ & $\begin{array}{c}0.0887 \\
(0.0918)\end{array}$ & $\begin{array}{c}0.0978 \\
(0.0984)\end{array}$ & $\begin{array}{c}0.0612 \\
(0.0717)\end{array}$ & $\begin{array}{c}0.0429 \\
(0.0584)\end{array}$ & $\begin{array}{c}0.0200 \\
(0.0417)\end{array}$ & $\begin{array}{l}-0.0830 \\
(-0.0333)\end{array}$ \\
\hline 30 & $\begin{array}{c}0.0281 \\
(0.0295)\end{array}$ & $\begin{array}{c}0.0296 \\
(0.0307)\end{array}$ & $\begin{array}{c}0.0327 \\
(0.0329)\end{array}$ & $\begin{array}{c}0.0204 \\
(0.0240)\end{array}$ & $\begin{array}{c}0.0143 \\
(0.0195)\end{array}$ & $\begin{array}{c}0.0067 \\
(0.0139)\end{array}$ & $\begin{array}{l}-0.0276 \\
(-0.0111)\end{array}$ \\
\hline 120 & $\begin{array}{c}0.0071 \\
(0.0075)\end{array}$ & $\begin{array}{c}0.0075 \\
(0.0077)\end{array}$ & $\begin{array}{c}0.0083 \\
(0.0084)\end{array}$ & $\begin{array}{c}0.0052 \\
(0.0060)\end{array}$ & $\begin{array}{c}0.0036 \\
(0.0049)\end{array}$ & $\begin{array}{c}0.0017 \\
(0.0035)\end{array}$ & $\begin{array}{c}-0.0069 \\
(-0.0028)\end{array}$ \\
\hline 350 & $\begin{array}{c}0.0025 \\
(0.0026)\end{array}$ & $\begin{array}{c}0.0026 \\
(0.0027)\end{array}$ & $\begin{array}{c}0.0029 \\
(0.0029)\end{array}$ & $\begin{array}{c}0.0018 \\
(0.0021)\end{array}$ & $\begin{array}{c}0.0013 \\
(0.0017)\end{array}$ & $\begin{array}{c}0.0006 \\
(0.0012)\end{array}$ & $\begin{array}{l}-0.0023 \\
(-0.0009)\end{array}$ \\
\hline
\end{tabular}

* In brackets: wage - real income elasticity when unions neglect non-wage income effects 
Table 4. Monetary Policy, Influential Competitors and Inefficiencies

\begin{tabular}{|c|c|c|c|c|c|c|c|}
\hline \multicolumn{4}{|c|}{ Monetary Accommodation } & \multicolumn{4}{|c|}{ Price Targeting } \\
\hline$\phi_{R}$ & 0.3 & 0.5 & 0.9 & -0.7 & -1.5 & -2.5 & -7.0 \\
\hline \multicolumn{8}{|c|}{$1-(\hat{Y} / Y)-$ Decentralized Labour Markets $(K=N)$} \\
\hline$K=N=10$ & $\begin{array}{c}0.0319 \\
(0.0481)^{*}\end{array}$ & $\begin{array}{c}0.0400 \\
(0.0516)\end{array}$ & $\begin{array}{c}0.0563 \\
(0.0586)\end{array}$ & $\begin{array}{c}-0.0083 \\
(0.0307)\end{array}$ & $\begin{array}{c}-0.0403 \\
(0.0171)\end{array}$ & $\begin{array}{l}-0.0799 \\
(0.0002)\end{array}$ & $\begin{array}{c}-0.2523 \\
(-0.0723)\end{array}$ \\
\hline 30 & $\begin{array}{c}0.0101 \\
(0.0152)\end{array}$ & $\begin{array}{c}0.0127 \\
(0.0162)\end{array}$ & $\begin{array}{c}0.0177 \\
(0.0184)\end{array}$ & $\begin{array}{c}-0.0023 \\
(0.0097)\end{array}$ & $\begin{array}{c}-0.0124 \\
(0.0054)\end{array}$ & $\begin{array}{c}-0.0249 \\
(0.0000)\end{array}$ & $\begin{array}{c}-0.0807 \\
(-0.0239)\end{array}$ \\
\hline 100 & $\begin{array}{c}0.0030 \\
(0.0044)\end{array}$ & $\begin{array}{c}0.0037 \\
(0.0047)\end{array}$ & $\begin{array}{c}0.0052 \\
(0.0054)\end{array}$ & $\begin{array}{l}-0.0006 \\
(0.0028)\end{array}$ & $\begin{array}{l}-0.0036 \\
(0.0015)\end{array}$ & $\begin{array}{l}-0.0073 \\
(0.0000)\end{array}$ & $\begin{array}{c}-0.0238 \\
(-0.0071)\end{array}$ \\
\hline 500 & $\begin{array}{c}0.0005 \\
(0.0008)\end{array}$ & $\begin{array}{c}0.0007 \\
(0.0009)\end{array}$ & $\begin{array}{c}0.0010 \\
(0.0010)\end{array}$ & $\begin{array}{c}-0.0001 \\
(0.0005)\end{array}$ & $\begin{array}{c}-0.0007 \\
(0.0003)\end{array}$ & $\begin{array}{c}-0.0014 \\
(0.0000)\end{array}$ & $\begin{array}{c}-0.0047 \\
(-0.0014)\end{array}$ \\
\hline 1000 & $\begin{array}{c}0.0002 \\
(0.0004)\end{array}$ & $\begin{array}{c}0.0003 \\
(0.0004)\end{array}$ & $\begin{array}{c}0.0005 \\
(0.0005)\end{array}$ & $\begin{array}{l}-0.0000 \\
(0.0002)\end{array}$ & $\begin{array}{c}-0.0003 \\
(0.0001)\end{array}$ & $\begin{array}{l}-0.0007 \\
(0.0000)\end{array}$ & $\begin{array}{c}-0.0023 \\
(-0.0007)\end{array}$ \\
\hline \multicolumn{8}{|c|}{$1-(\hat{Y} / Y)-$ Varying Centralization $(\zeta=1 / K)$} \\
\hline \multirow[t]{2}{*}{$N=1000, K=5$} & $\begin{array}{c}-0.0492 \\
(-0.0131)\end{array}$ & $\begin{array}{c}-0.0350 \\
(-0.0092)\end{array}$ & $\begin{array}{c}-0.0066 \\
(-0.0014)\end{array}$ & $\begin{array}{l}-0.1189 \\
(-00317)\end{array}$ & $\begin{array}{l}-0.1735 \\
-00458)\end{array}$ & $\begin{array}{c}-0.2402 \\
(-00627)\end{array}$ & $\begin{array}{c}-0.5191 \\
-01289)\end{array}$ \\
\hline & -0.0216 & -0.0153 & -0.0026 & -0.0532 & -0.0782 & -0.1091 & -0.2443 \\
\hline 10 & $(-0.0056)$ & $(-0.0038)$ & $(-0.0003)$ & $(-0.0142)$ & $(-0.0209)$ & $(-0.0292)$ & $(-0.0640)$ \\
\hline \multirow{2}{*}{30} & -0.0064 & -0.0044 & -0.0004 & -0.0163 & -0.0242 & -0.0340 & -0.0781 \\
\hline & $(-0.0014)$ & $(-0.0008)$ & $(0.0002)$ & $(-0.0041)$ & $(-0.0064)$ & $(-0.0091)$ & $(-0.0213)$ \\
\hline \multirow{2}{*}{120} & -0.0011 & -0.0006 & 0.0003 & -0.0036 & -0.0056 & -0.0081 & -0.0192 \\
\hline & $(0.0000)$ & $(0.0001)$ & $(0.0004)$ & $(-0.0007)$ & $(-0.0013)$ & $(-0.0020)$ & $(-0.0053)$ \\
\hline \multirow{2}{*}{350} & -0.0000 & 0.0001 & 0.0004 & -0.0009 & -0.0016 & -0.0025 & -0.0066 \\
\hline & $(0.0003)$ & $(0.0004)$ & $(0.0005)$ & $(0.0000)$ & $(-0.0002)$ & $(-0.0005)$ & $(-0.0018)$ \\
\hline
\end{tabular}

* In brackets: inefficiencies when unions neglect non-wage income effects 